\title{
Experimental validation of an algorithm for masonry vaults reinforced by the $\Omega-W r a p$ technique
}

\author{
L. Anania, A. Badalà, M. Cuomo \& G. D'Agata \\ Dipartimento di Ingegneria Civile, Università di Catania, Italia
}

\begin{abstract}
Assessment of the effects of the application of advanced materials and new technologies on traditional structures has assumed a major relevance within the ongoing debate on the preservation of historic buildings. The aim of the present paper is to discuss the validity of analytical models, by means of experimental investigations carried out on masonry arches reinforced with an innovative technology proposed by the same author and based on the use of CFRP strips, with a special configuration called an " $\Omega$-Wrap". A theoretical prediction of ultimate strength was derived in agreement with the occurrences observed during the experiments (masonry crushing, FRP rupture, debonding, sliding along the mortar joint). The results of the experimental trials allowed us not only to validate the proposed analytical derivations but also to evaluate the impact of these innovative reinforcement configurations on the strength of masonry arches. So a lower bound limit analysis approach was developed which can handle with the shear strength of each ideal sections given by the Mohr-Coulomb friction law (for the mortar joint) and other non linear Italian Code relations (for CFRP $\Omega$ wrap reinforcement) at a given level of normal compressive stress, resulting from the previous step. In this way the associated flow rule holds at each step for the shear failure mechanism also without dilatancy.

Keywords: arch masonry structure strengthening FRP experimental test.
\end{abstract}

\section{Introduction}

The masonry arch bridge was the oldest and the most popular form of bridge in the word before the development of high strength material, and it proved to be durable and reliable with limited maintenance. With regards to the many issues 
associated to the restoration of the historical masonry arches the use of composite material was the most used by the workers in the field of the civil engineering. In fact this materials, thanks to its very low weight, it does not influence the behavior of the structure under vertical loads, while is able to defense the structure against horizontal actions. From the analytical point of view, with the development of computer based numerical methods, the FE method has also been used to simulate the complex behavior of the masonry arches, vaults (Choo et al. [1], Hendry et al. [2], Page [3]) even when associated to innovative material. But, often the input parameters of the real constitutive models are so difficult to determine experimentally. For this reason, plastic (limit) analysis methods are now commonly used to determine the ultimate load carrying capacities of masonry arch. According to plastic theory if a thrust line can be found which satisfies both the equilibrium and yield conditions, then the applied load will be a lower bound on the true plastic collapse load.

In the follow, an approximated methodology for approaching the lower bound limit analysis (Heyman [4]) of masonry arch (and barrel vaults), reinforced by CFRP is illustrated. It is based on the central idea of carrying out a series of lower bound limit analyses. In each of them shear strength is assumed constant and given by the Mohr-Coulomb limit at the corresponding compression force, in each mortar joint, resulting from the previous step. This analytical approach was carried out in order to predict the collapse mechanism hinge pattern of an innovative technology for the retrofitting for masonry vaults by means of CFRP, proposed by Badalà et al. [5] and named $\Omega$-Wrap.

The basic ideas of the " $\Omega$-Wrap" technology is to give high stiffness to the CFRP strips by wrapping it around a high resistance mortar core cast and molded in site (Figure 1).

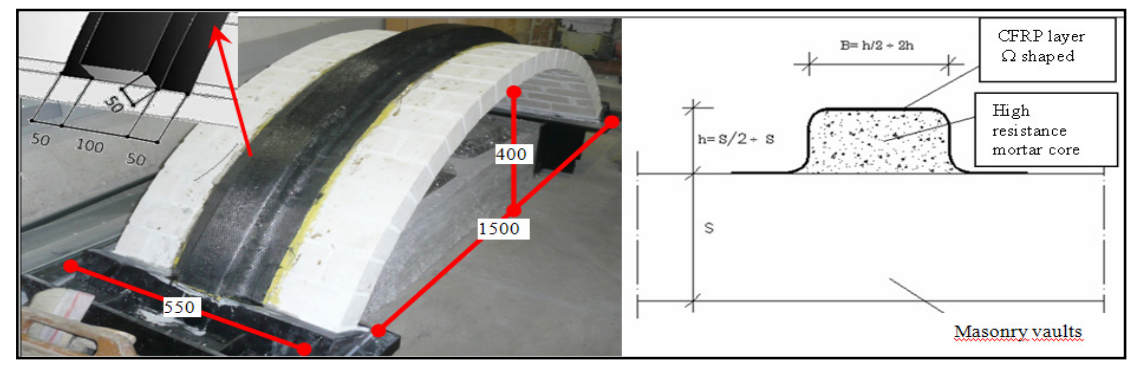

(a)

(b)

Figure 1: (a) Model of the barrel vault tested, dimensions in $[\mathrm{mm}]$; (b) $\Omega$-Wrap reinforcement.

The analytical approach is also capable of taking into account the shear mechanisms according to the dowel effect at the interface between masonry and CFRP. So, an incremental procedure was carried out in which for each single step the limit analysis problem was solved considering a constant value of the shear resistance derived taking into account the normal stress at the previous step 
according to Coulomb law. The latter theory was implemented in Mathematica software offering numerical simulation. The software so obtained was used to illustrate the case studied, i.e. assessment of arches loaded with vertical point load or with specific constrains.

\section{The analytical derivation}

In this paper the limit analysis procedure is referred only to the case of ring vaults with constant thickness and circular generatrix, reinforced by the $\Omega$-Wrap technique, although it is also valid for arch and vaults of generic generatrix and variable thickness. Some details of the application of this method to the case of unreinforced and classically CFRP strip reinforced vaults can be found in Badalà et al. $[6,7]$.

The method is based on limit analysis and uses the static theorem approach (safe - or lower-bound - and uniqueness theorems) to determine the ultimate capacity of the structures analyzed by means of an optimization process.

The proposed limit analysis formulation relies on a number of assumptions necessary for the validity of the limit theorems (Milani et al. [9]):

- $\quad$ No tensile strength for both the masonry and of the mortar rib of the $\Omega$ Wrap, with rigid-perfectly plastic behaviour in compression;

- $\quad$ Bricks have limited compressive strength

- No compression and flexional rigidity of the FRP reinforcement, with rigid-perfectly plastic behaviour in tension;

- Transversal plane sections conservation;

- Delamination of the CFRP is not considered explicitly.

- Constant CFRP reinforcement "dowel effect" shear strength

- $\quad$ Plane geometry;

- $\quad$ The blocks initially fit perfectly together;

It is well known, the interface CFRP-masonry behaviour is very far from being elastic-perfectly plastic, rather it's strongly non linear with softening, as is typical for fracture cohesive mechanics. Therefore the results obtained have to be considered only an approximation of the real load-bearing capacity of the masonry vaults reinforced by CFRP. In spite the necessary aforementioned considerations, the methodology results in very good agreement with available original experimental data.

\subsection{The sample geometry}

For that purpose, the geometry is described by decomposing the entire masonry vault (or arch) in a series of equally spaced short segments (or fictitious "voussoirs") limited by sections oriented perpendicularly to the axis (Fig. 2).

Figure 3 shows the forces acting on the elementary fictitious voussoir; where $\mathrm{N}, \mathrm{V}, \mathrm{M}$ indicate the characteristics of internal forces, $\mathrm{W}$ is the weight of the voussoir (including $\Omega$-Wrap system) and F[i] is the force acting on it, amplified by $\lambda$ and applied at the distance $d[i]$ from the " $y$ " axis of symmetry. There are accordingly $3(n+1)$ internal forces and $3 n$ equilibrium equations, being $n$ the 
number of voussoir. With an appropriate choice of the three undetermined unknowns, the equations of equilibrium can be conveniently reformulated obtaining the internal forces as a function of them.

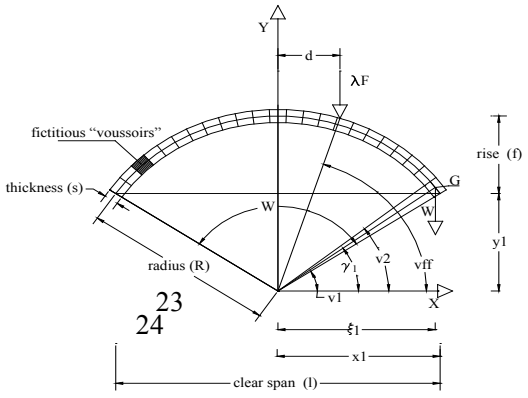

Figure 2: Geometry discretization.

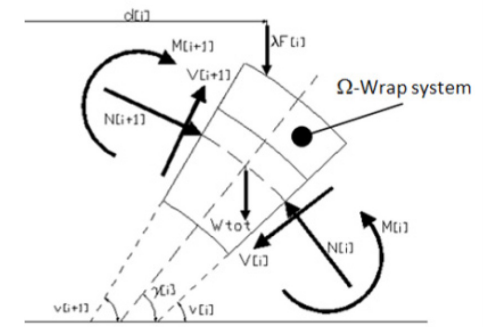

Figure 3: Forces acting on the infinitesimal slice of arch (single voussoir).

\subsection{The M-N domain}

The admissibility domain of interaction between bending moment and axial force (M-N domain) is calculated taking into account that the limit strength in tension of CFRP, assumed herein rigid- perfectly plastic as aforementioned, is evaluated with CNR-DT200/2004 formulas [10].

The M-N domain, for a rectangular section reinforced by the $\Omega$-Wrap reinforcement, is derived considering four different mechanisms both for negative and positive bending moment, for a total of eight expressions. With reference to Fig.4, we have

$s \quad$ thickness of masonry arch;

$p_{r} \quad$ effective width of the portion of masonry barrel vault collaborating with the reinforcement, evaluated according to CNR-DT200/2004 with relation to a reinforcement width given by $p_{c}+2 a$;

$\mathrm{h}_{\mathrm{c}}, \mathrm{p}_{\mathrm{c}} \quad$ thickness and width of $\Omega$-Wrap system;

$t_{f} \quad$ thickness of FRP reinforcement;

$b_{f, \text { sup }} \quad$ width of FRP reinforcement at the top of $\Omega$-Wrap system;

$a \quad$ width of the FRP reinforcement swaged at the extrados of the vault;

$\alpha f_{c m} \quad$ compressive strength of masonry;

$\sigma_{\text {fmaxb }}$ tensile strength of C-FRP adherent to the masonry evaluated according to CNR-DT200/2004 (with account for delamination);

$\sigma_{\text {fmaxc }}$ tensile strength of C-FRP adherent to the mortar core of the $\Omega$-Wrap system, evaluated according to CNR-DT200/2004(with account for delamination);

$\alpha f_{c c} \quad$ compressive strength of mortar core of the $\Omega$-Wrap system. 
Considering a positive bending moment, four mechanisms can be assessed, according with the position of the neutral axes, obtaining four pair of parametric equations (2)-(9). In a same way it is possible to determinate the other four pair of parametric eqn. (10)-(17) of N-M domain for negative curvature.

From each pair of parametric expressions it is easy to get the limit static admissibility conditions, for bending moment and axial force, in the form: $\mathrm{M}\left[\mathrm{M}_{\mathrm{i}}(\mathrm{N})\right.$, with $\mathrm{i}=1,2, . .8$.

The convex limit domain $M-N$ envelope of the eight functions $M_{i}(N)$, obtained for the case of $\Omega$-Wrap system reinforcement is compared in Fig. 6 with the one of the unreinforced masonry vault and of the classical reinforcement with only one strip, with the same width of $\Omega$-Wrap $(200 \mathrm{~mm})$ and the same total specific weight $\left(300 \mathrm{~g} / \mathrm{m}^{2}\right)$ of uniaxial fabric of CFRP, attached at the extrados of the vault.

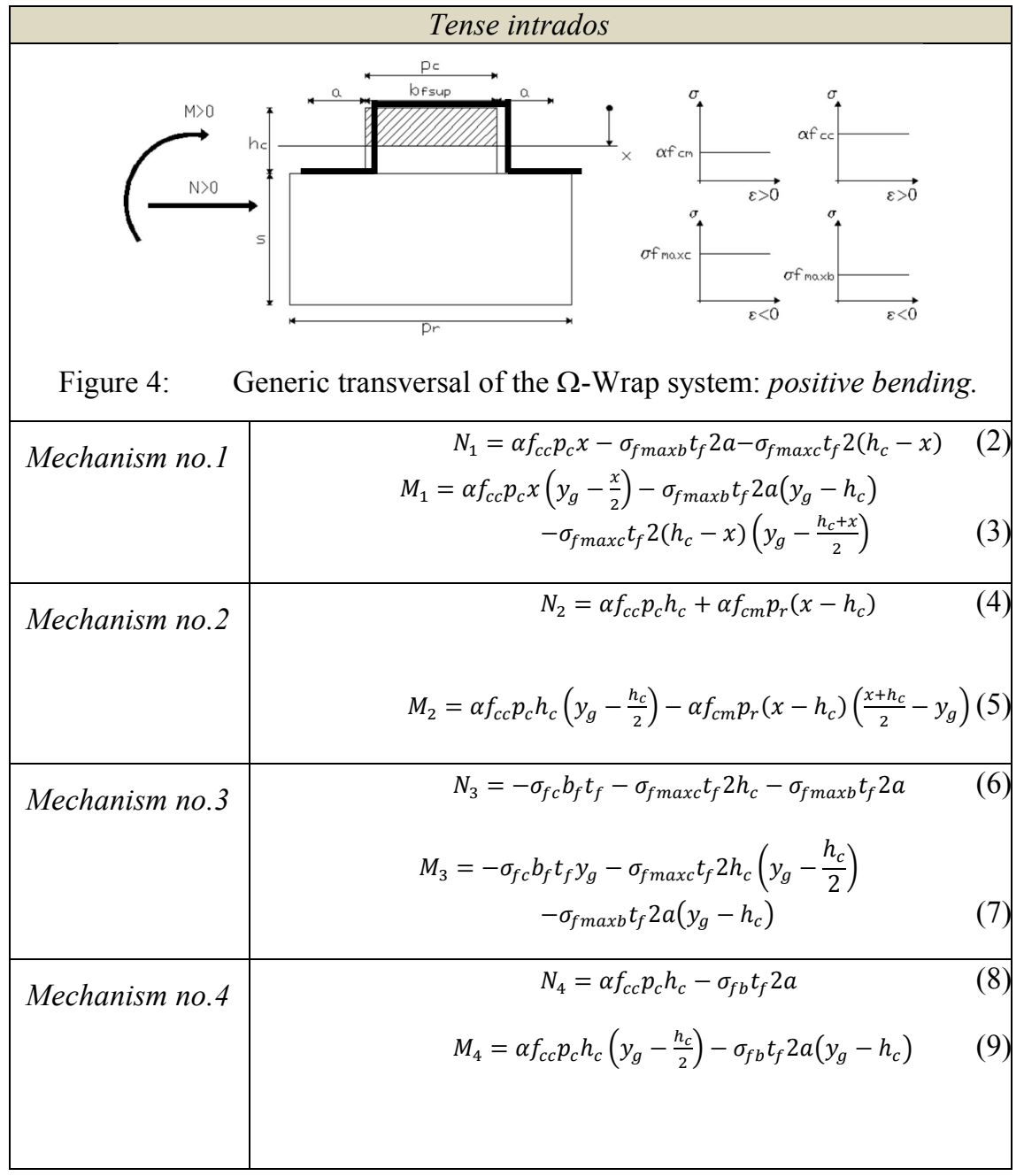




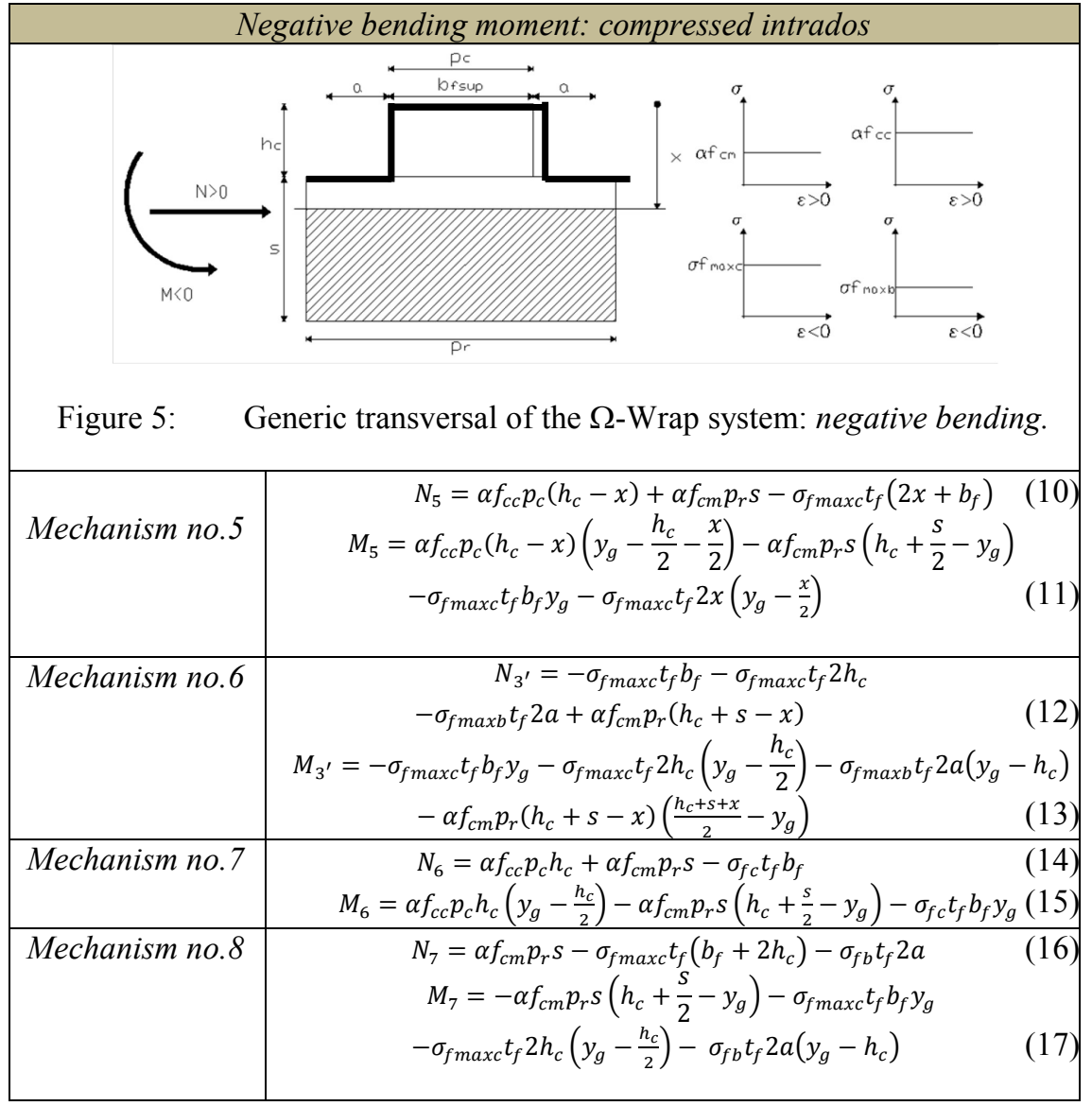

\subsection{Shear strength}

Sliding consists in relative movements of two parts along the mortar joint and it occurs when the friction mechanism is not capable of balancing the shear of the external load on the cross section with a corresponding shear force. The shear resistance of the $\Omega$-Wrap reinforced masonry vault is caused by the following main components:

$$
V_{\text {lim }}=\tau_{m} p s+P_{d, \text { sup }}+P_{d, \text { inf }}
$$

In eqn. (18), the shear strength of the mortar joint and the shear strength of the mortar core of the $\Omega$-Wrap system " $\tau_{\mathrm{m}}$ ", were evaluated according to the Italian Code D.M. 14/01/2008 and CNR-DT200/2004, while the term " $\mathrm{P}_{\mathrm{d}}$ " represents the contribute of dowel effect. The latter was evaluated according to the formulation reported in Badalà et al. [11] with eqn. (19). 


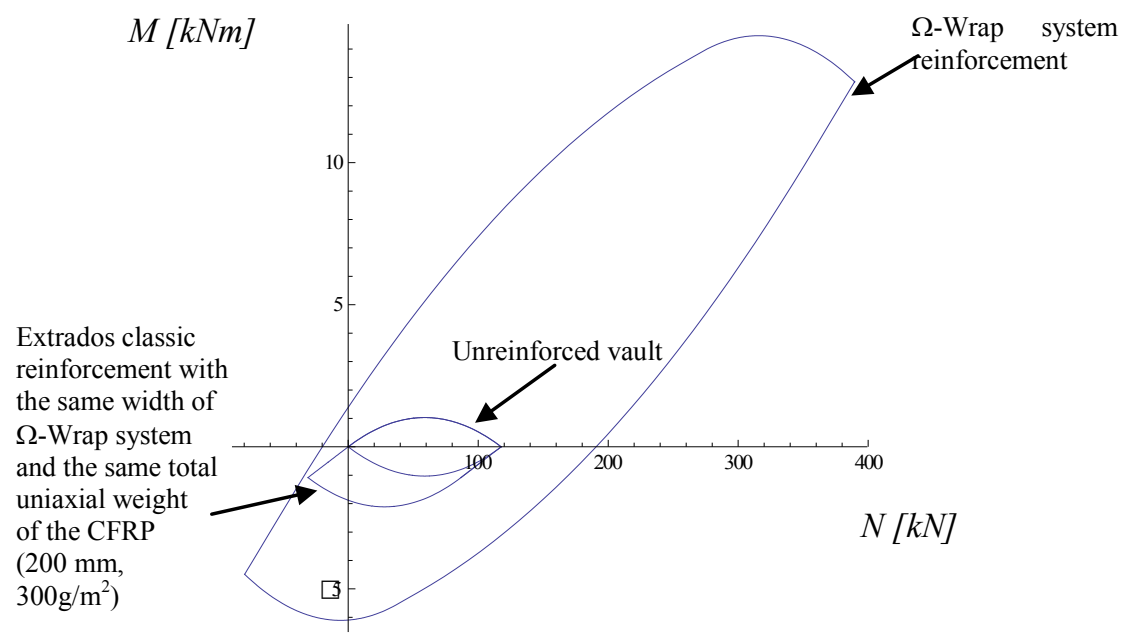

Figure 6: Comparison of the interaction domain $\mathrm{M}-\mathrm{N}$ for the two case of unreinforced and reinforced with the $\Omega$-Wrap system masonry barrel vault.

$$
P_{d}=b_{f} t_{f} E_{f}\left(\frac{1}{\cos \vartheta_{C R}}-1\right) \sin \vartheta_{C R}
$$

In the model proposed the critical angle $q_{\mathrm{CR}}$ is correlated to the cohesive mode I specific fracture energy " $\Gamma_{I}$ " of the interface between the under layer of masonry soaked with the primer, (that remains attached to the CFRP composite after the delamination process), and the underlying substrate of masonry, where the primer was unable to penetrate.

We observe, however, that while in the case of the traditional reinforcement the contribution of the dowel-effect is the most significant, in the case of the $\Omega$ Wrap reinforcement it is small if compared to the other contributions. With this formulation an associate friction rule is assumed depending on the level of normal stress acting on each single section, even if this provides a very small friction modulus between bricks and mortar.

\subsection{Formulation of the optimization problem}

The lower bound limit analysis formulation leads to the follow non linear optimization problem to finding the limit multiplier $\lambda$ of the applied load system:

$$
\begin{aligned}
& \lambda_{c}=\max _{\lambda, x} \lambda \\
& \text { s.to }\left\{\begin{array}{cc}
M[i] \leq M_{j}(N[i]) ; & j=1,2,3,4 \\
M[i] \geq M_{k}(N[i]) ; & k=5,6,7,8 \quad i=1,2, \ldots, n+1 \\
|V| \leq V_{R d, m}+V_{R d, c}+P_{d, a} &
\end{array}\right\}
\end{aligned}
$$


In these formulations with "i" is indicated each of the joints of the vault, being " $n$ " the number of fictitious voussoirs, while " $j$ " and " $k$ " are the two series of the four relations for the M-N domain, in explicit form, for positive and negative sign of the rotation of the cross section, respectively. The vector $\mathrm{X}$ collects the three independent interfacial forces that determine all the other internal force in the vault. The functional dependence from the variables $\lambda$ and $\mathrm{X}$ is omitted for simplifying the notation.

This formulation is valid for fixed values of the shear resistance in each section of the vaults, so we are within the framework of the validity of the Radenkovic's second theorem for non-associated flow rules [12].

\subsection{Analytical assessment of the collapse load of the sample}

The calcareous bricks employed are $7 \times 7 \times 15 \mathrm{~cm}^{3}$ arranged in a single sheet, with 23 rows of blocks, and bedridden with mortar of hydrated lime and cement of class M2.5 N/mm ${ }^{2}$ according to Italian code. The arch geometry is plotted in fig. 1. The $\Omega$-Wrap system nucleus dimensions are $5 \mathrm{~cm}$ in height and $10 \mathrm{~cm}$ in width, and it's cast on the extrados of the vault. The CFRP is placed around the core and swaged on the extrados of masonry for a width equal to $5 \mathrm{~cm}$ at each sides, and is made of two layers of uniaxial arranged at right angles to each other, forming a balanced biaxial reinforcement with equivalent thickness of $0.167 \mathrm{~mm}$ in each orthogonal directions. Table 1 reports the main mechanical properties of the materials used, some of which were experimental determined, The design value of the intermediate delamination tensile strength of CFRP is determined multiplying by three the ones related to the overboard delamination, according to what prescribed by CNR-DT200/2004 for concrete.

In the case of the barrel vault the reinforcement should be uniformly applied along the generatrix with a suggested step given by CNR-DT200/2004: $p r=$ $3 t+b_{f}$ where $b_{f}$ " is the width of the adopted strengthening system and " $\mathrm{t}$ " is the thickness of the vault. In this case $p r=41 \mathrm{~cm}, \mathrm{t}=7 \mathrm{~cm} b_{f}=20 \mathrm{~cm}$.

The model was implemented by constraining the abutments one as fixed the other one as mobile. The extreme mortar joints, near the supports, were implemented by given infinite value to the resistant shear, which was in order to take account of the presence, in real structures, of the walls supporting the upper floors.

The proposed heuristic algorithm herein proposed consists of the following steps:

1) Solving problem (20) for a value of the shear strength of each section of the vault corresponding to a null value of the axial force.

2) Solving again the same problem (20), considering a shear resistance corresponding to compressive stress found in conjunction with the limit load obtained from the previous problem resolution;

3) Repeated step 2) until result satisfies the two following conditions:

A) no more change of the collapse mechanism;

B) convergence of the resulting limit load multiplier to the assumed final value, within a fixed numerical tolerance. 
Table 1: $\quad$ The main mechanical properties of the materials used.

\begin{tabular}{|c|c|c|c|c|c|}
\hline Property & Material & Value & Property & Material & Value \\
\hline \multirow{5}{*}{$\begin{array}{c}\text { Compressive } \\
\text { strength } \\
\text { (cubic, } \\
\text { average) } \\
\text { [MPa] }\end{array}$} & Brick & 12.6 & \multirow{5}{*}{$\begin{array}{c}\text { Young } \\
\text { modulus } \\
\text { (average, } \\
\text { secant at } \\
\text { break point) } \\
{[\mathrm{MPa}]}\end{array}$} & Brick & 9500 \\
\hline & Mortar & 2.5 & & Mortar & 675 \\
\hline & Masonry & 4.1 & & Masonry & 4100 \\
\hline & CFRP & 0 & & CFRP & 230000 \\
\hline & $\begin{array}{l}\text { Mortar of the } \\
\Omega \text {-Wrap core }\end{array}$ & 54.39 & & $\begin{array}{l}\text { Mortar of the } \\
\Omega \text {-Wrap core }\end{array}$ & 2882 \\
\hline \multirow{5}{*}{$\begin{array}{c}\text { Tensile } \\
\text { strength } \\
\text { (average) } \\
{[\mathrm{MPa}]}\end{array}$} & Brick & 1.2 & \multirow{5}{*}{$\begin{array}{c}\text { Density } \\
\text { (average) } \\
{\left[\mathrm{kNm}^{-3}\right]}\end{array}$} & Brick & 17.5 \\
\hline & Mortar & 0.2 & & Mortar & 20.0 \\
\hline & Masonry & 0 & & Masonry & 18.0 \\
\hline & CFRP & 4830 & & CFRP & 14.8 \\
\hline & $\begin{array}{l}\text { Mortar of the } \\
\Omega \text {-Wrap core }\end{array}$ & 3.87 & & $\begin{array}{l}\text { Mortar of the } \\
\Omega \text {-Wrap core }\end{array}$ & 20.0 \\
\hline $\begin{array}{c}\text { Initial shear } \\
\text { strength } \\
\text { (average) } \\
{[\mathrm{MPa}]}\end{array}$ & Masonry & 0.1540 .20 & $\begin{array}{c}\text { Overboard } \\
\text { design tensile } \\
\text { strength of } \\
\text { CFRP with } \\
\text { different } \\
\text { materials } \\
(\mathrm{CNR}- \\
\text { DT200/2004) } \\
{[\mathrm{MPa}]}\end{array}$ & Masonry & 308.7 \\
\hline
\end{tabular}

At each step the average value of the normal stress acting on the rib and masonry sections, respectively, is computed in approximate way from the linear distribution obtained applying the Navier's law to the homogenized cross section as better explain in Badalà et al. [11]. With these data the collapse load $\mathrm{F}_{\mathrm{u}}=\mathrm{l}_{\mathrm{c}} \mathrm{F}=$ $38.16 \mathrm{kN}$ is obtained. The plastic hinges pattern is represented in figure 7 and it is defined by the following sequence: $M=\{(1,1)(17,3)(17,1)(24,2)\}$. The former number in brackets, is the section number where the hinge occurs, the latter provides the active mechanism ( $1=$ extrados hinge, $2=$ intrados hinge, $3=$ shear failure improper hinge).

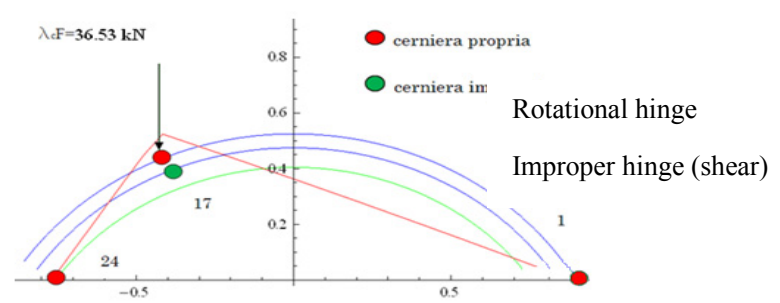

Figure 7: Analytical mechanism: plastic hinges distribution. 


\section{Experimental investigation}

The proposed analytical derivations were validated through an experimental investigation on a suite sample in scale 1:2 of a typical traditional one ring masonry arch with a span of 3 . The sample was $n$ the past object of other test but with different restrain condition. For this reason the sample was, firstly repairing. The repairing technique applied to the vault consists, first, in cleaning the damaged surface, joints etc., then in the removing and substituting the damaged bricks and finally in filling the mortar joints' cracks with special resins. In this investigation, voissours at the extremity were properly constrained in order to simulate the influence of the upper floor in the real structures. To this aim a shear restrain was realized by means of steel profile as reported in fig. 8 .

In order to have a very simple failure mode, the load was applied at $1 / 4$ of the clear span of the arch, by means of a screw jack placed in series to a load cell of $250 \mathrm{KN}$ capacity. A ball joint and a sliding bearing realized by means of two steel plates with interposed a Teflon layer of $0.3 \mathrm{~mm}$ in thickness, permits the transmission of only the vertical component of the applied load related to the imposed displacement. A properly realized wood element, reinforced by means of a steel L 60x6 profile, is capable of distributing the load along the whole transversal section of the vault. A special sliding bearing support allows the measurement of the horizontal thrust by means of two cells of $25 \mathrm{kN}$ capacity located on the impost at the opposite side to the loading point (fig. 10). Thirteen displacement transducers are distributed along the directrix of the arch. Eight strain gauges are placed along the CFRP material as shown in figure 11 .

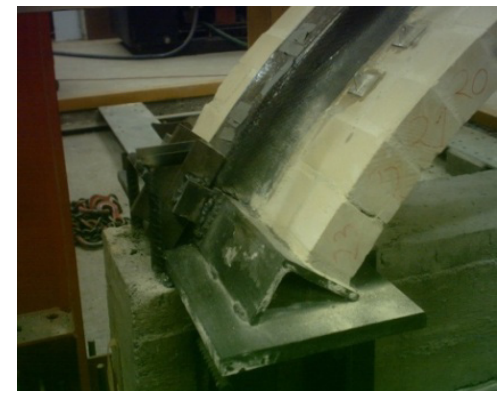

Figure 8: Shear restrain at the fixed abutment.

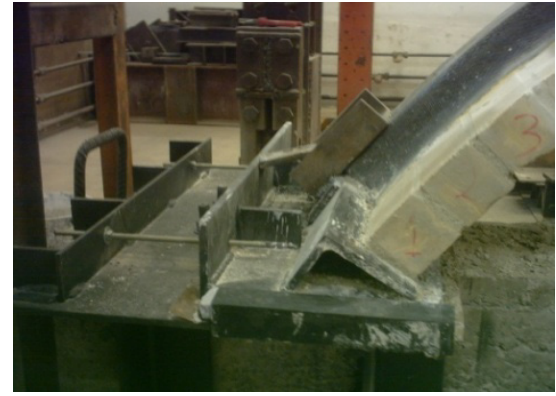

Figure 9: Shear restrain at the mobile impost.

The limit load experimentally determined was $42.0 \mathrm{kN}$, the numerical incremental procedure gave a final result of $35.21 \mathrm{kN}$, with a very close accordance with the experimental data, also for the limit mechanism plotted in figure 13 .

In figure 12 , the vibrations around the theoretical value are due to the real tensile strength of the masonry, indeed neglected in the analytical approach. The algorithm is able to catch the damage evolution in the vault structure throughout different mechanisms. Figure 14 reports the damage at the final step. 


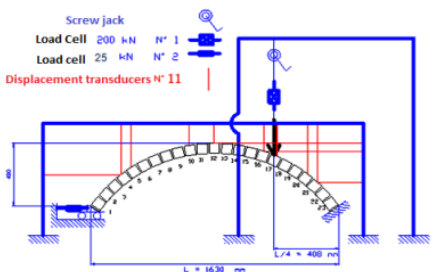

Figure 10: Testing equipment scheme.

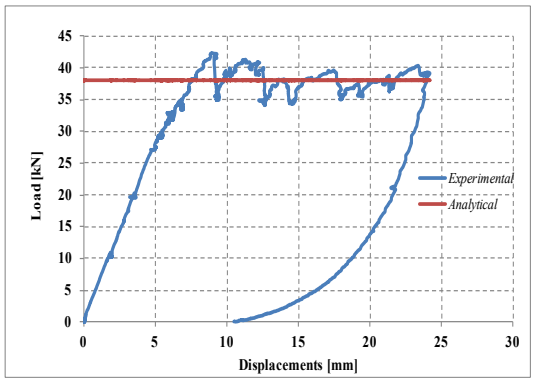

Figure 12: Testing equipment scheme.

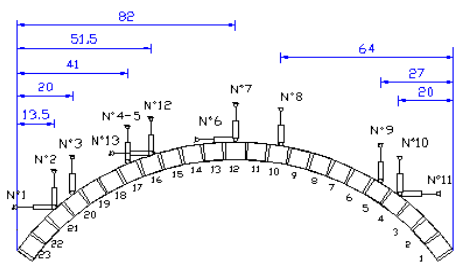

Figure 11: Instrumented sample.

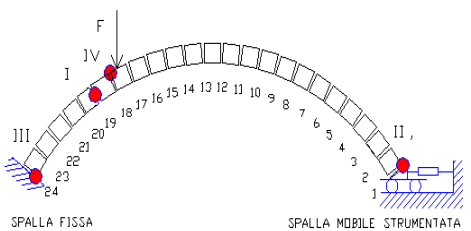

Figure 13: Experimental collapse load.

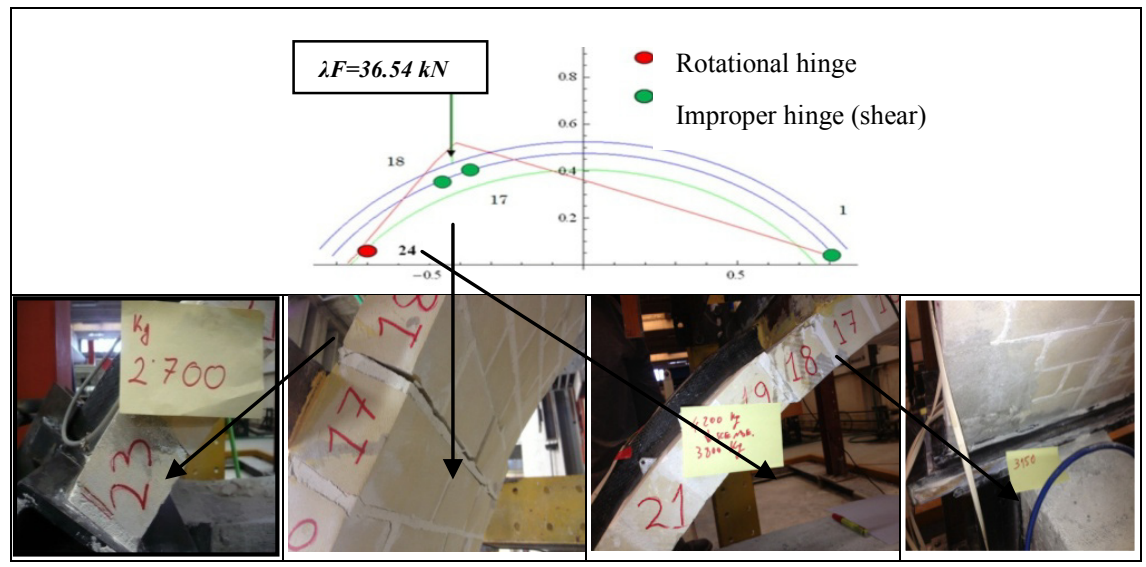

Figure 14: Comparison between theoretical and real damage in the vault. 


\section{Conclusions}

The proposed analytical procedure is able to highlights all the capability of the new strengthening technique. In fact the experimental and numerical data are in good agreement both in terms of ultimate load and collapse mode.

Besides the numerical $\mathrm{M}-\mathrm{N}$ domains show the great improvement of bearing capacity in respect to no strengthened one. In fact, a gain of more than 52 times greater is obtained. The proposed system is able to fulfill the requirement of a greater dissipation capacity for structures subjected to dynamic input if compared to the traditional strengthening systems. This is due to the better capability of the composite of working in compression without any unsuitable buckling effect thanks both to its curve shell shape and to the adherence between a good substrate and composite.

\section{References}

[1] Choo, B.S., Coutie, M.G., and Gong, N.G., Finite element analysis of masonry arch bridges using tapered elements, to be published.

[2] Hendry, A.W., Davies, S.R., and Royles, R., Test on stone masonry arch at Bridgemill - Girvan, TRRL contractor report 7, 1985.

[3] Page, J., Load test to collapse on two arch bridges at Torksey and Shinafoot, TRRL research report 159, 1988.

[4] Heyman J., The Stone Skeleton, Structural Engineering of Masonry Architecture, Cambridge University Press, 1995.

[5] Anania L., Badalà A., D'Agata G. "The behavior under thermal loads of the " $\Omega$-wrap" strategy For the strengthening of the masonry vault structures" proceedings of The Eleventh East Asia-Pacific Conference on Structural Engineering \& Construction (EASEC-11), Taipei, Taiwan, 2008.

[6] A. Badalà, M. Cuomo, G. D’Agata, Analisi limite di volte a botte rinforzate con CFRP, GIMC2008, Alghero, 10-12 Settembre, 2008.

[7] A. Badalà, M. Cuomo, G. D’Agata, Analisi limite di volte a botte rinforzate con C-FRP-AIMETA2009-Ancona, 14-17 Settembre, 2009.

[8] G. Milani, E. Milani, A. Tralli, Upper Bound limit analysis model for FRPreinforced masonry curved structures. Part I: Unreinforced masonry failure surfaces, Computers and Structures 87 (2009) 1516-1533.

[9] G. Milani, E. Milani, A. Tralli, Upper Bound limit analysis model for FRPreinforced masonry curved structures. Part II: Structural analyses, Computers and Structures 87 (2009) 1534-1558.

[10] CNR-DT 200/2004, Istruzioni per la Progettazione, l'Esecuzione ed il Controllo di Interventi di Consolidamento Statico mediante l'utilizzo di Compositi Fibrorinforzati-Materiali, strutture in c.a. e in c.a.p., strutture murarie, Versione Sottoposta ad Inchiesta.

[11] A. Badalà, M. Cuomo, G. D’Agata, Limit Analysis Of Cfrp Reinforced Masonry Vaults: An Approximated Incremental Algorithm GIMC 2010.

[12] J. Lubliner, Plasticity Theory, Macmillan Publishing Company-New York, 1990. 